SILVA, S.C. et al. Verminose em rebanhos ovinos. PUBVET, Londrina, V. 5, N. 1, Ed. 148, Art. 996, 2011.

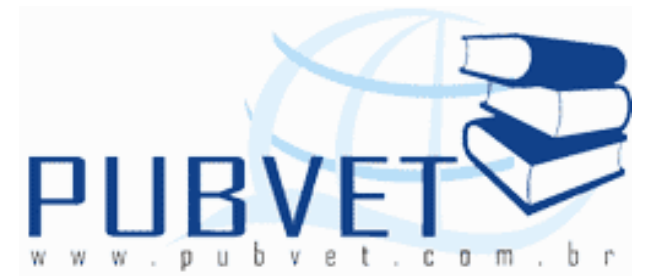

PUBVET, Publicações em Medicina Veterinária e Zootecnia.

\title{
Verminose em rebanhos ovinos
}

Suelen Corrêa da Silva2 , Alexandre Agostinho Mexia' ${ }^{1}$, Jocilaine Garcia1, Osvaldo Martins de Souza ${ }^{1}$, Tatiane Botini ${ }^{1}$, Giselde Marques Angreves Silva1, Lucien Bissi da Freiria², Leonardo André Gomes²

${ }^{1}$ Professor do Departamento de Zootecnia. Universidade do Estado de Mato Grosso (UNEMAT).

2 Alunos de graduação do Curso de Zootecnia da Universidade do Estado de Mato Grosso. Autor para correspondência: suelencorrea_z@hotmail.com

\section{Resumo}

$\mathrm{Na}$ ovinocultura nacional, o maior problema enfrentado no que diz respeito ao manejo sanitário, são as infecções por endoparasitas. O objetivo deste trabalho foi detectar a ocorrência de resistência de nematódeos gastrintestinais em rebanhos ovinos na região de Pontes e Lacerda-MT, avaliando a eficácia anti-helmíntica dos princípios a base de Abamectina, Closantel, Doramectina, Fosfato de Levamisol, Ivermectina, Moxidectin e Sulfóxido de Albendazol. Foram utilizados 520 fêmeas SRD (Sem Raça Definida) padrão Santa Inês, com diferentes idades pertencentes a propriedades distintas. Estes ovinos foram distribuídos aleatoriamente e monitorados pelo método de contagem de ovos por grama de fezes (OPG) Os resultados apresentados demonstraram que a redução na média de eficácia dos principio ativos utilizados nas propriedades foram de $15,40 \%, 60,32 \%, 85,30 \%, 94,61 \%, 67,43 \%, 92,18 \%, 43,53 \%$, para 
SILVA, S.C. et al. Verminose em rebanhos ovinos. PUBVET, Londrina, V. 5, N. 1, Ed. 148, Art. 996, 2011.

Abamectina, Closantel, Doramectina, Fosfato de Levamisol, Ivermectina, Moxidectin e Sulfóxido de Albendazol, respectivamente. Os princípios ativos utilizados apresentaram ações diferentes, mesmo todas as propriedades sendo de similar região, constatando que a resistência dos nematódeos esta relacionada ao manejo e as alternativas de controle adotado em cada propriedade.

Palavras-chave: eficiência, fosfato de levamisol, OPG, ovelhas.

\section{Worms in sheep flocks}

\section{Abstract}

In national ovineculture, the biggest problem about the sanitary management are the endoparasites infections. The aim of this work was to detect the resistance occurrence of gastrointestinal nematodes in sheep livestock in Pontes e Lacerda region, evaluating the efficiency of anthelmintic molecules of: Abamectine, Closantel, Doramectine, Levamisol Fosfate, Ivermectine, Moxidectin and Albendazole Sulfacid. It was used 520 undefined genotype female sheeps, Santa Ines pattern, with different ages belonging to different properties.These ovines were distributed and monitorated by faecal egg counts reduction test(FECRT). The results presented showed that the reduction on the average efficiency of the molecules used in the properties were $15,40 \%, 60,32 \%, 85,30 \%, 94,61 \%, 67,43 \%, 92,18 \%, 43,53 \%$, para Abamectine, Closantel, Doramectine, Levamisol Fosfate, Ivermectine, Moxidectin and Albendazole Sulfacid respectivelly. The molecules used showed different actions, even all the proprieties are in similar region, assuring the resistance of nematodes is related to the management and the control alternatives adopted in each property.

Keywords: efficiency, levamisol fosfate, FECRT, sheep. 
SILVA, S.C. et al. Verminose em rebanhos ovinos. PUBVET, Londrina, V. 5, N. 1, Ed. 148, Art. 996, 2011.

\section{INTRODUÇÃO}

O mundo tem uma população ovina de aproximadamente 1,2 bilhões, ocupando grande parte dos ambientes impróprios para a agricultura, como regiões montanhosas e semiáridas (SÁ e SÁ, 2005). Segundo o IBGE (2008), o plantel de ovinos no Brasil em 2008 estava em torno de 16.628.571 milhões de cabeças, destes, 9.371.905 milhões se encontram na região Nordeste do país e 1.110 .550 milhões no Centro Oeste. O Mato Grosso apontava um efetivo de 439.689 mil cabeças de ovinos.

Devido a crescente demanda pela carne ovina, a ovinocultura de corte está se tornando uma atividade, cada vez mais atraente para a diversificação da produção agropecuária. Esse fato aliado às características dos ovinos de serem animais dóceis, de fácil manejo e que não necessitam de áreas extensas, quando comparados com os bovinos, vem despertando o interesse de produtores rurais detentores de pequenas áreas, a desenvolver a criação de ovinos como alternativa econômica em suas propriedades, principalmente quando próximas a centros consumidores (VECHI, 2004).

Índices zootécnicos comprovam potencial produtivo dos ovinos, associado ao fato de esses animais apresentarem boa adaptação à região Centro Oeste. A vantagem climática e a rusticidade de algumas raças, propícias à reprodução da espécie em praticamente todos os meses do ano, acarretam constância no fornecimento de produtos. Essa é uma das vantagens competitivas da região Centro-Oeste, visto que as regiões Sul e Nordeste apresentam-se com sazonalidade na oferta de animais terminados (GONTIJO NETO, 2005).

$\mathrm{Na}$ ovinocultura nacional, o maior problema enfrentado no que diz respeito ao manejo sanitário, são as infecções por endoparasitoses. As verminoses interferem negativamente na qualidade de dois dos principais produtos da ovinocultura, lã e carne, e inclusive, no desenvolvimento corporal dos animais. Os nematódeos são um dos principais responsáveis pela baixa produtividade 
SILVA, S.C. et al. Verminose em rebanhos ovinos. PUBVET, Londrina, V. 5, N. 1, Ed. 148, Art. 996, 2011.

inviabilizando o sistema de produção, causando prejuízos irreparáveis a atividade pecuária (SOARES et al., 2009).

Os efeitos do parasitismo no desempenho produtivo do rebanho se manifesta de várias formas, conforme as espécies presentes, a intensidade da infecção e a categoria e/ou estado fisiológico e nutricional dos animais. O impacto sobre a produção é conseqüência do atraso no crescimento, redução dos parâmetros produtivos e mortes das categorias mais susceptíveis (VIEIRA, 2003).

A resistência dos nematódeos em pequenos ruminantes encontra-se disseminada no mundo inteiro. O controle destes parasitos e o diagnóstico precoce, especialmente em $H$. contortus, devem ser preconizados a fim de viabilizar economicamente a criação de ovinos. O conhecimento dos vários aspectos genéticos deste fenômeno, poderá aumentar a vida útil dos fármacos atualmente utilizados, e consequentemente tentar preservar a susceptibilidade dos parasitos (MELO, 2005).

É necessário relacionar todo um sistema de produção com o controle da verminose. Por ser a verminose um fator tão agravante ao rebanho ovino, contribuindo para reduzir a produtividade e a viabilidade econômica da produção (OTTO et al., 1994).

O presente trabalho teve por objetivo detectar a ocorrência de resistência de nematódeos gastrintestinais em rebanhos ovinos na região de Pontes e Lacerda, sudoeste de Mato Grosso, Brasil.

\section{REVISÃO BIBLIOGRÁFICA}

Praticamente $100 \%$ dos animais criados a campo albergam uma ou mais espécies de nematódeos. O parasitismo, entretanto, não é sinônimo de doença, pois, geralmente, os animais de um rebanho se encontram em boas condições de saúde, ou pelo menos, a maioria deles. Isto decorre do fato dos hospedeiros terem mecanismos imunológicos que possibilitam, na maioria das vezes, manter a população de endoparasitas sob controle. Quando isto ocorre, 
SILVA, S.C. et al. Verminose em rebanhos ovinos. PUBVET, Londrina, V. 5, N. 1, Ed. 148, Art. 996, 2011.

pode-se afirmar que a relação parasita - hospedeiro se encontra em equilíbrio. Entretanto, esta situação de equilíbrio pode ser alterada por diversos fatores como o clima, o estado nutricional, a idade e o estado fisiológico dos animais, etc. O rompimento deste equilíbrio é, muitas vezes, produzido pela ação do próprio homem (AMARANTE, 2004).

\subsection{DEFINIÇÃO DA DOENÇA}

Dentre os problemas de ordem sanitária que prejudicam o desempenho de ovinos, as doenças provocadas por parasitas são responsáveis por grandes prejuízos, merecendo a atenção de todos os que estejam envolvidos nesse setor. Um parasito, de maneira abrangente, pode ser definido como um ser vivo que se aloja em outro ser vivo, de espécie diferente da sua, que é chamado de hospedeiro, dele recebendo vantagens e provocando-lhe algum dano (BELLUZO et al., 2001).

Os sinais do parasitismo gastrintestinal podem variar com o grau da infecção. Animais com um parasitismo intenso, geralmente demonstram sinais de fraqueza, perda de peso severa e diarréia. Podem apresentar edema submandibular, isto é, um aumento de volume na região da mandíbula que normalmente é acompanhado por anemia intensa (SÁ, e SÁ,. 1994).

Já na subclinica, presente em 90 a $98 \%$ dos casos, não apresentados sinais clínicos típicos de uma verminose, caracteriza-se por provocar retardo no crescimento, diminuição do ganho de peso, diminuição da produção leiteira, retardo nas atividades reprodutivas e predisposição a outras doenças. Tais manifestações, confundíveis com problemas nutricionais e carências minerais, aliadas a ausência de uma sintomatologia típica de verminose, induzem a uma interpretação errônea e consequentemente a não adoção de medidas adequadas de controle (PEREIRA et al., 2005).

Os vermes mais patogênicos e que causam maior mortalidade nos rebanhos pertencem aos gêneros Haemonchus e Trichostrongylus (VERÍSSIMO, 2005). Em geral, as infecções são mistas, ou seja, os animais 
SILVA, S.C. et al. Verminose em rebanhos ovinos. PUBVET, Londrina, V. 5, N. 1, Ed. 148, Art. 996, 2011.

são parasitados por diferentes espécies ao mesmo tempo. As espécies de maior ocorrência, além do Haemonchus contortus e Trichostrongylus colubriformis, nas regiões tropicais são Strongyloides spp., Cooperia spp. e Oesophagostomum columbianum (MACIEL, 2008).

O Haemonchus contortus aparece em maior frequência nas épocas quentes do ano e habita o abomasso dos animais, por ser um verme sugador, causa anemia severa, inapetência, prostração, diarréia, edema submandibular (papeira), perda na qualidade da lã. Já o Trichostrongylus colubriformis é um verme que tem maior incidência nos meses de outono e habita o intestino delgado. É um parasita que causa redução do apetite, edema submandibular e diarréia preta e fétida, o que diferencia da diarréia causada pela entrada dos animais na pastagem (HASTENPFLUG e WOMME, 2009).

Os animais se infectam durante o pastejo e dependendo de vários fatores, como raça, idade e estado nutricional o impacto negativo sobre a produtividade individual e do rebanho pode ser representativo (GATTO, 2007).

Dados do Sindicato Nacional da Indústria de Produtos para Saúde Animal do ano de 2003, apontam que as despesas com produtos para ovinos e caprinos representam $8 \%$ do mercado veterinário brasileiro e que os antiparasitários representam $36,5 \%$ do faturamento dessas Indústrias, refletindo bem a importância dos parasitos e a necessidade do controle destes no contexto da saúde animal (GENNARI e AMARANTE, 2005).

\subsection{CICLO DE VIDA DO PARASITO}

Estima-se que 5-10\% dos nematódeos gastrintestinais encontram-se no animal e $90-95 \%$ na pastagem na forma de vida livre. Sendo assim, além do controle baseado na aplicação de anti-helmínticos, o controle estratégico de endoparasitos necessita de um manejo de pastagens que propicie condições para uma rebrota rápida e abundante, satisfatório valor nutritivo de forragem, eficiente aproveitamento da forragem produzida, além da adoção de 
SILVA, S.C. et al. Verminose em rebanhos ovinos. PUBVET, Londrina, V. 5, N. 1, Ed. 148, Art. 996, 2011.

estratégias de diminuição da população de larvas infectantes (QUADROS, 2004).

A biologia destes parasitos tem um padrão muito semelhante. Seu ciclo de vida (Figura 1) obedece a dois momentos distintos: a fase parasitária que ocorre dentro do hospedeiro, e a fase não parasitária ou de vida livre, no meio ambiente, envolvendo no total sete fases de vida - ovo, estádios larvais L1, L2, L3 e L4, adulto jovem (L5) e adulto maduro (MACIEL et al., 2006).

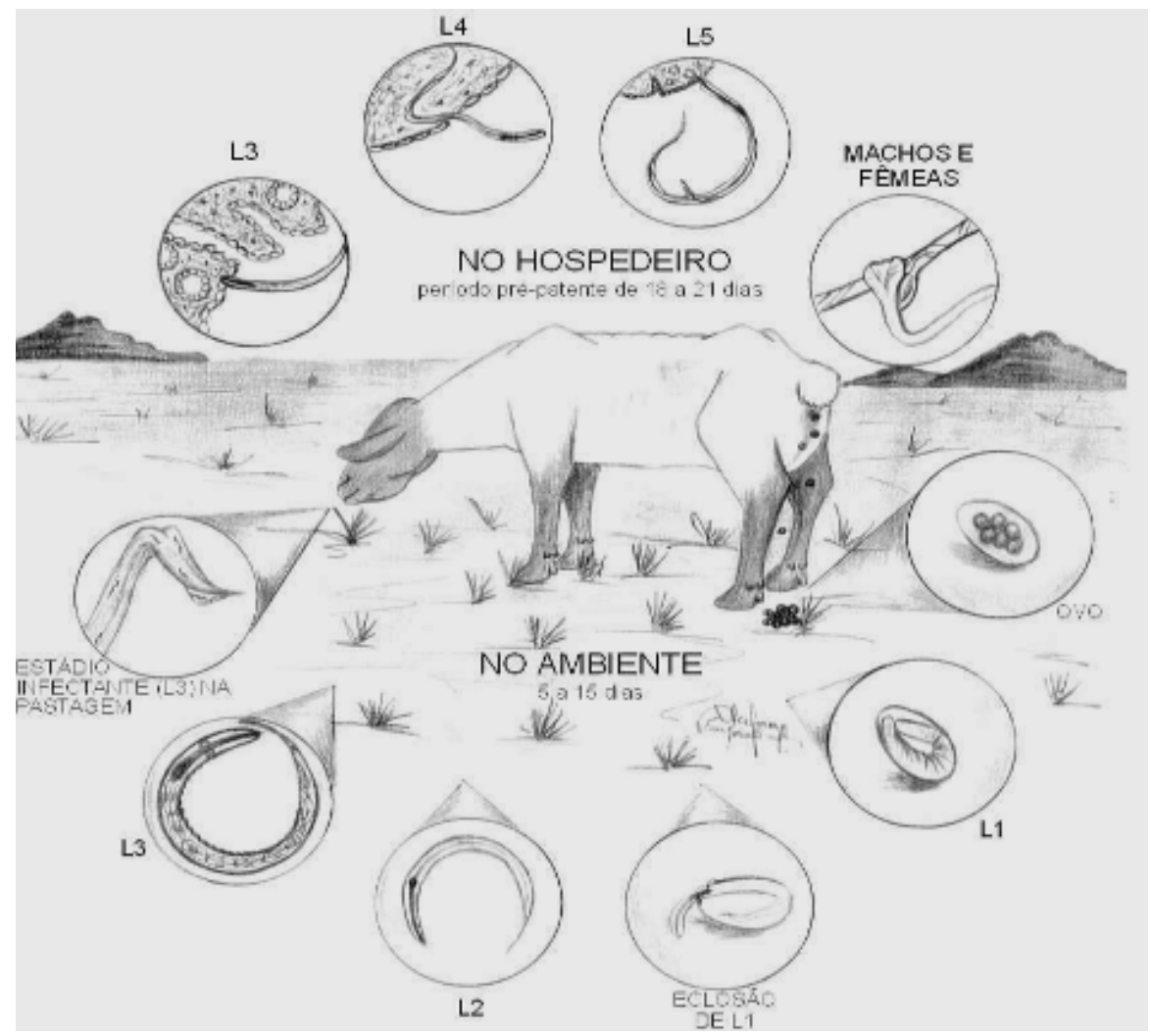

Figura 1. Ciclo de vida do nematóide. (Fonte: Moraes, 2002).

No bolo fecal, e nas primeiras 24 horas, os ovos embrionados evoluem para larvas de primeiro estágio (L1), as quais sofrem muda para a segunda fase (L2). Ambas alimentam-se de bactérias e outros microorganismos. As L2 mudam para larvas de terceiro estágio (L3), as L3 após abandonarem o bolo fecal, migram para a vegetação adjacente e posteriormente são ingeridas 
SILVA, S.C. et al. Verminose em rebanhos ovinos. PUBVET, Londrina, V. 5, N. 1, Ed. 148, Art. 996, 2011.

pelos animais. O ciclo de ovos a L3 se completa entre 7 a 10 dias ou podem permanecer viáveis por dias ou meses (FONSECA, 2006).

A larva L3 então consumida pelos ovinos pode evoluir para a forma adulta (larva L4) ou permanecer em estágio dormente (hipobiose) dentro do animal. A hipobiose ocorre para que a larva sobreviva a condições ambientais desfavoráveis, como no inverno. Em condições estressantes para o ovino, ou quando cai a sua resistência, a larva em hipobiose sai da dormência e pode se manifestar. O tempo de vida do parasita nas pastagens é muito variável, existem relatos de que as larvas podem sobreviver até 1 ano no pasto, o que dificulta o controle da verminose através de períodos curtos de descanso dos piquetes (SÁ e SÁ, 2001).

No tubo digestivo, as larvas infectantes mudam para o quarto estágio (L4) ou adulto imaturo, aumentam de tamanho, diferenciam os órgãos e se tornam adultos. Os vermes adultos copulam e as fêmeas iniciam a postura (LOURENÇO e SANTELLO, 2007). A quantidade de ovos eliminada pelos parasitas está na dependência de fatores como a quantidade de ovos produzidos diariamente, no qual depende do gênero (RUFINO, 2007). Assim, cada fêmea produz uma grande quantidade de ovos. Cada ovo, encontrando as condições ambientais favoráveis, origina uma larva contaminante (LOURENÇO e SANTELLO, 2007).

Em relação aos animais, a idade, o estado nutricional, o parto, a lactação, a raça, o parasita, o manejo, o nascimento, o desmame, a superpopulação e a introdução de animais novos no rebanho são fatores que contribuem para aumentar a população de parasitas no organismo dos animais (QUADROS \& VIELMO, 2004).

De acordo com Pereira et al. (2005) uma modificação do ciclo de vida pode acontecer quando as condições ambientais são desfavoráveis como o frio, a dessecação ou até mesmo a resistência do hospedeiro, levando as larvas ingeridas a permanecerem inibidas na mucosa do aparelho digestivo, prolongando assim o período pré-patente. O fim da inibição pode ser ocasionado pela chegada da primavera, diminuição da resistência, 
SILVA, S.C. et al. Verminose em rebanhos ovinos. PUBVET, Londrina, V. 5, N. 1, Ed. 148, Art. 996, 2011.

aproximação do parto, introdução dos animais em áreas livres de parasitas ou até mesmo por tratamento anti-helmíntico (drogas que não atuam em larvas inibidas).

Ainda, sabe-se que essas larvas são bastante resistentes, podendo permanecer por vários meses nas pastagens. Nas horas mais quentes e ensolaradas elas se dirigem para as partes inferiores das plantas, chegando a penetrar na superfície do solo em busca de um ambiente mais propício para a sua sobrevivência (BELLUZO et al., 2001).

\subsection{ANIMAIS SUSCEPTIVEIS A VERMINOSE}

A interação entre o parasita e o sistema de defesa do hospedeiro pode resultar na morte e eliminação dos vermes, o que ocorre nos animais resistentes ou, no outro extremo, na persistência dos parasitas, aparentemente intactos, o que ocorre nos animais susceptíveis. Em uma situação intermediária, a infecção pode persistir, porém com prejuízos à sobrevivência e à fecundidade dos nematódeos. Isto ocorre nos animais com resistência intermediária. A enfermidade clínica (verminose) manifesta-se especialmente nos animais susceptíveis do rebanho (AMARANTE, 2004).

Em relação ao hospedeiro susceptível, as características como: espécie, idade, sexo, raça, infecções concomitantes, dentre outras, são preponderantes para o aparecimento de quadros patológicos de maior ou menor intensidade (OLIVEIRA et al, 2008). Destacam-se ainda aqueles que têm influência na resposta imunológica, como no caso de animais mantidos em condições nutricionais precárias ou animais gestantes, na qual apresentam maior susceptibilidade às infecções por nematódeos. Os animais mais jovens também são mais susceptíveis à infecção. A raça é outro fator que tem merecido grande atenção em estudos em todo o mundo (GENNARI E AMARANTE, 2005). 
SILVA, S.C. et al. Verminose em rebanhos ovinos. PUBVET, Londrina, V. 5, N. 1, Ed. 148, Art. 996, 2011.

\subsubsection{Periparto}

Em um sistema de produção, quer seja para leite quer seja para carne , a chave para o sucesso do negócio está principalmente no adequado manejo da fêmea prenhe. Indiscutivelmente o período do periparto, isto é, o período que envolve as três semanas anteriores e as três semanas posteriores ao parto, é considerado crítico. Nele ocorrem importantes mudanças metabólicas e fisiológicas, necessárias para suportar o estado fisiológico. Qualquer falha no manejo destas fêmeas pode comprometer a saúde e a produção das mesmas (SUCUPIRA, 2010).

No período do periparto as ovelhas se tornam mais susceptíveis às infecções por nematódeos gastrintestinais o que provoca aumento no número de ovos eliminados nas fezes e conseqüentemente, aumento da contaminação da pastagem. O fenômeno do periparto é devido ao aumento na fecundidade dos vermes adultos, à retomada do desenvolvimento de larvas hipobióticas e ao estabelecimento de novas larvas infectantes, sendo que os dois últimos acarretam marcado aumento na carga parasitária de helmintos adultos. Após a desmama dos cordeiros, a resposta imunológica se restabelece provocando redução acentuada nas contagens de ovos por grama de fezes (OPG) (AMARANTE, 2008a).

Sasa et al. (2008) analisaram duas fases, pré-parto e pós-parto, e concluíram que o período pós-parto foi o mais crítico $(P<0,01)$, com valor médio de 4387 OPG, enquanto que o período pré-parto apresentou valor médio de 679 OPG (Figura 2). Observaram forte tendência dos animais a apresentarem maior contagem de OPG próxima ao parto, na qual esses valores começaram a aumentar, significativamente, a partir dos 10 dias antes do parto até os 10 dias após o parto, ressaltando-se dessa forma, a maior sensibilidade dos animais nesse período. 
SILVA, S.C. et al. Verminose em rebanhos ovinos. PUBVET, Londrina, V. 5, N. 1, Ed. 148, Art. 996, 2011.

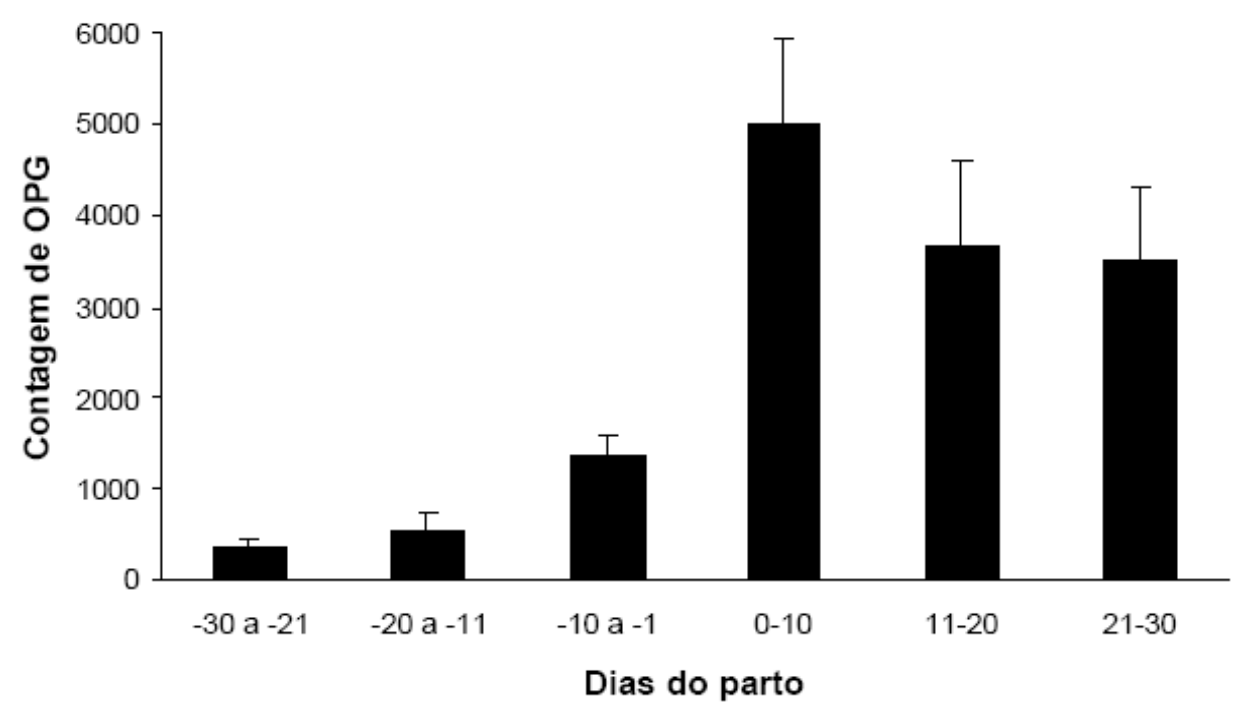

Figura 2. Médias e erros-padrão da contagens de ovos por grama (OPG) de ovelhas Santa Inês $(n=45)$ antes e após o parto. (Fonte: Sasa et al, 2008).

Segundo Katiki et al. (2007), as mudanças hormonais associadas com a lactação, às dietas pobres e o estresse interferem negativamente na imunidade da ovelha, e resultam em aumento da fixação, da fecundidade dos parasitas e da diminuição da capacidade do organismo em expulsar vermes adultos.

As principais razões para a imunossupressão no periparto são: o balanço energético negativo, a colostrogênese e o próprio parto. No final da gestação e no início da lactação a as fêmeas apresentam balanço energético e protéico negativo, uma vez que nessa fase há menor ingestão de alimentos. Além disso, o estresse físico, calor, baixo conforto, instalações inadequadas, entre outros pode diminuir ainda mais a ingestão de alimentos e agravando a imunussupressão. Ainda, os mecanismos desencadeantes do parto, principalmente o domínio estrogênico, favorecem a produção e a transferência de imunoglobulinas para a glândula mamária para a formação do colostro em detrimento das defesas celulares do próprio animal (GOFF e HORST, 1997 citado por CARVALHO et al., 2006).

Segundo Chagas et al. (2008) a elevação do OPG das matrizes também foi influenciada pela época de parição (Figura 3). Os nascimentos ocorreram 
SILVA, S.C. et al. Verminose em rebanhos ovinos. PUBVET, Londrina, V. 5, N. 1, Ed. 148, Art. 996, 2011.

em quatro épocas: março e abril de 2006, janeiro e fevereiro de 2007, julho de 2007 e, por último, em novembro e dezembro de 2007. OPG médio foi diminuindo ao longo da estação seca e aumentou na estação chuvosa de 2006/2007, principalmente entre outubro de 2006 e abril de 2007. O OPG foi reduzido novamente na estação seca de 2007, com pico em agosto de 2007, logo após a parição e precipitação atípica ocorridos em julho.

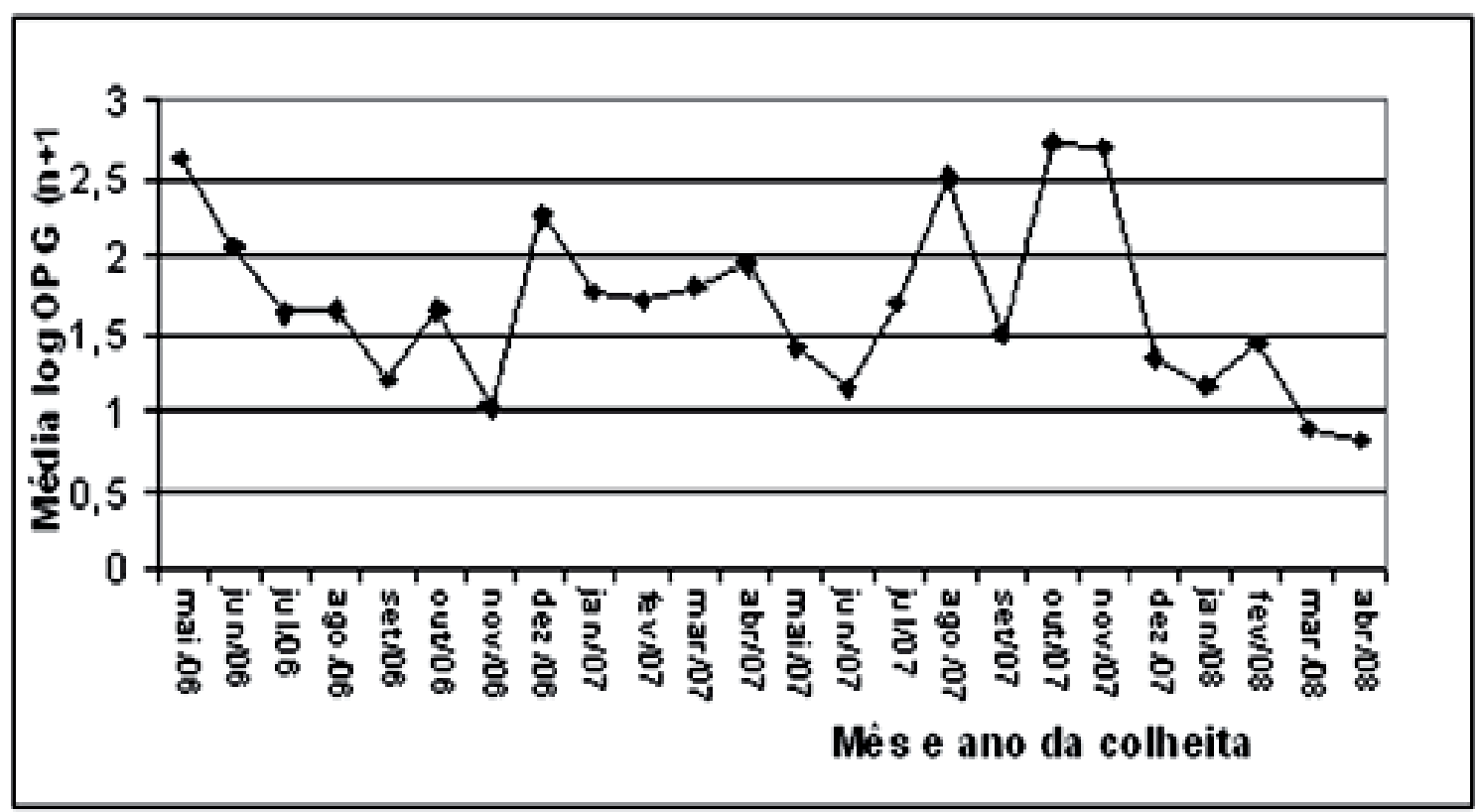

Figura 3. Médias mensais de temperatura e precipitação pluviométrica obtidas na estação meteorológica da Embrapa Pecuária Sudeste, São Carlos, SP. (Fonte: Chagas et al., 2008).

\subsubsection{Influência da raça}

O aparecimento de populações de nematódeos com resistência aos antihelmínticos tem dificultado a profilaxia das helmintoses em ruminantes. Como a resistência às infecções helmínticas apresenta herdabilidade a eficiência do controle da verminose pode ser aumentada a partir da identificação dos indivíduos resistentes (AMARANTE, 2008a).

A adaptação de um genótipo ou raça a determinada condição do ambiente ou de criação não se faz sentir tão somente em parâmetros fisiológicos como 
SILVA, S.C. et al. Verminose em rebanhos ovinos. PUBVET, Londrina, V. 5, N. 1, Ed. 148, Art. 996, 2011.

temperatura corporal, freqüência respiratória, etc. Na verdade, considera-se adaptado a uma condição de produção aquele genótipo ou raça que é capaz de produzir e, principalmente, no caso de animais produtores de carne, se reproduzir com eficiência sob tais condições. (FACó et al., 2008).

Animais de raças importadas, em sua maioria são originários de regiões de clima temperado e que, conseqüentemente, apresentam grande susceptibilidade a algumas espécies de parasitas que são abundantes em regiões tropicais (AGROPOINT, 2007).

Portanto raças naturalizadas brasileiras tendem a serem menos susceptíveis à verminose do que raças que foram importadas de países com clima e agentes patológicos diferentes aos nossos (KATIKI et al., 2007).

Alguns estudos demonstraram que a resistência à infecção por Haemonchus contortus é superior em animais das raças Crioula Lanada e Santa Inês. Um dos problemas é que as raças anteriormente citadas (resistentes) apresentam algumas características relacionadas à produção consideradas inferiores. Animais da raça Santa Inês, por exemplo, produzem carcaça de qualidade inferior a de animais Suffolk ou Ile de France. No caso da produção de cordeiros destinados ao abate, uma alternativa seria o cruzamento de matrizes da raça mais resistente com reprodutores de uma raça mais produtiva (AMARANTE, 2008b).

Os ovinos considerados naturalmente resistentes ao H.contortus, possuem parasitos menores, com menor oviposição, sendo os ovos eliminados mais cedo e de forma mais eficiente, os mecanismos biológicos envolvidos na resistência natural a parasitos são regulados por genes de ação seqüencial; o que torna a resistência determinada geneticamente. Como na maioria das características de importância econômica, vários genes podem estar envolvidos no controle da resistência (NUNES et al., 2007).

$\mathrm{Na}$ composição do rebanho a escolha da raça materna para produção intensiva de carne de cordeiro deve levar em conta o grau de resistência à verminose, pois as matrizes compõem a maioria dos animais dentro de um plantel. Manter animais com elevada susceptibilidade a endoparasitas em 
SILVA, S.C. et al. Verminose em rebanhos ovinos. PUBVET, Londrina, V. 5, N. 1, Ed. 148, Art. 996, 2011.

sistemas de pastejo, com lotações elevadas, pode não ser viável do ponto de vista econômico, e da sustentabilidade do sistema, em função da dificuldade no controle da verminose. Ao contrário, optar por matrizes de maior resistência é o caminho correto para o êxito em uma produção intensificada e sustentável (BUENO et al., 2008).

Mexia (2002) verificou que ovelhas Santa Inês apresentaram maior resistência comparada às raças Texel e Bergamácia, os resultados referentes à contagem de OPG das ovelhas Santa Inês, Texel e Bergamácia estão expressos na Tabela 1. A raça Santa Inês apresentou maior resistência $(P \leq 0,05)$ ao endoparasitismo que as raças Texel e Bergamácia, sendo que estas duas últimas não diferiram entre si $(P>0,05)$.

Tabela 1: Contagem média de ovos por grama de fezes (OPG) nos exames coprológicos das ovelhas nos diferentes grupos genéticos, de fevereiro 2001 a janeiro 2002, no noroeste do Paraná

\begin{tabular}{lc}
\hline Grupo genético & OPG \\
\hline Santa Inês & $838.58 \pm 76.14^{\mathrm{a}}$ \\
Texel & $1240.31 \pm 228.65^{\mathrm{b}}$ \\
Bergamácia & $1821.33 \pm 442.07^{\mathrm{b}}$ \\
\hline Médias seguidas de letras diferentes são diferentes $(\mathrm{P} \leq 0,05)$, pelo teste de T. (Fonte: Mexia, \\
\end{tabular}

Amarante et al. (1992) observaram que o OPG médio apresentado pelas ovelhas da raça Romney-Marsh foi significativamente inferior aos apresentados pelas ovelhas Merino Australiano e Ideal, enquanto que as ovelhas Corriedale apresentaram um comportamento intermediário entre a primeira e as duas últimas raças (Tabela 2 ). 
SILVA, S.C. et al. Verminose em rebanhos ovinos. PUBVET, Londrina, V. 5, N. 1, Ed. 148, Art. 996, 2011.

Tabela 2: OPG médio de ovelhas de quatro raças obtido antes do parto, durante a lactação e após o desmame dos cordeiros.

\begin{tabular}{lcccc}
\hline \multirow{2}{*}{$\begin{array}{l}\text { Raças } \\
\text { Ovinas }\end{array}$} & $\begin{array}{c}\text { OPG médio } \\
\text { parto }\end{array}$ & $\begin{array}{c}\text { Durante a } \\
\text { lactação }\end{array}$ & $\begin{array}{c}\text { Após o } \\
\text { desmame }\end{array}$ & Comparação \\
\cline { 2 - 4 } $\begin{array}{l}\text { Merino } \\
\text { Australiano }\end{array}$ & $2891,3 \mathrm{~B}$ & $2213,0 \mathrm{~B}$ & $573,2 \mathrm{~A}$ & $\mathrm{~b}$ \\
$\begin{array}{l}\text { Ideal } \\
\text { Romney }\end{array}$ & $1930,9 \mathrm{AB}$ & $4737,8 \mathrm{~B}$ & $721,1 \mathrm{~A}$ & $\mathrm{~b}$ \\
$\begin{array}{l}\text { Marsh } \\
\text { Corriedale }\end{array}$ & $205,1 \mathrm{~B}$ & $930,1 \mathrm{~A}$ & $142,2 \mathrm{~A}$ & $\mathrm{a}$ \\
\hline $\begin{array}{l}\text { Letras maiúsculas desiguais na linha e letras minúsculas desiguais na coluna representam } \\
\text { diferença significativa a nível de 5\%. (Fonte: Amarante et al., 1992). }\end{array}$
\end{tabular}

Quanto a susceptibilidade á verminose, além da diferença entre as raças ovinas, é possível realizar a seleção de animais resistentes dentro de cada raça, diante disso, faz-se necessário que se defina a raça melhor adaptada ás nossas condições ambientais, com base em dados de produtividade e rusticidade, pois existe a possibilidade de que nessa raça sejam selecionadas animais com maior resistência aos nematódeos gastrintestinais (AMARANTE et al., 1992).

A seleção se baseia na escolha correta dos indivíduos que produzirão descendentes e leva em consideração características morfológicas e/ou produtivas que se deseja ver expressa

na geração seguinte. Portanto é uma ferramenta que tem o objetivo de melhoria ou fixação de alguma característica de importante (SIDER et al., 2008).

\subsubsection{Idade do animal}

De forma geral, os animais até a puberdade apresentam grande susceptibilidade à verminose. O grau de infecção dos cordeiros varia conforme as condições de manejo e a intensidade de contaminação das pastagens. Em algumas criações de ovinos, são observadas elevadas contagens de OPG em cordeiros mesmo antes da desmama, ou seja, em animais com menos de dois 
SILVA, S.C. et al. Verminose em rebanhos ovinos. PUBVET, Londrina, V. 5, N. 1, Ed. 148, Art. 996, 2011.

meses de idade. Medidas efetivas de controle de verminose são indispensáveis na recria dos animais jovens. Caso essas medidas não sejam eficazes, a mortalidade e a redução no ganho de peso dos animais poderão causar prejuízos bastante sérios aos ovinocultores (AMARANTE, 2008a).

Em relação aos cordeiros no pós desmame, a interrupção da lactação leva a uma condição de stress, tornando estes animais também mais sensíveis à verminose e, se houver como agravante um manejo sanitário inadequado, culminará no aumento da mortalidade. Desta forma, cria-se um ciclo que produz um rápido aumento no grau de infestação dos animais e dos campos, sendo maior o problema quando o cordeiro permanece por um período prolongado de tempo com a mãe, estabelecendo-se uma competição entre mães e filhos pelos pastos e concentrados disponíveis, sendo que, a própria ovelha contamina com ovos de parasitas as pastagens que servem de alimento para os cordeiros (SÁ e OTTO, 2001).

Há uma tendência de maior contaminação dos animais a partir de 40 dias de idade, na qual os cordeiros começam a ingerir forragem uma vez que, quanto mais velhos, mais dependem das pastagens e, assim favorecendo também a ingestão de helmintos (BERNARDI et al., 2005). Em casos de alta lotação das pastagens, é comum cordeiros com 45 dias de idade diminuírem sua taxa de crescimento e até morrerem por causa dos vermes (OTTO et al, 1994).

O manejo das pastagens para prevenir a infecção por nematóides gastrintestinais requer tempo e, sobretudo planejamento. Isto porque fatores como: densidade populacional, idade dos animais, taxa de lotação e tempo de descanso da pastagem estão diretamente relacionados com a profilaxia das verminoses. Nas pastagens irrigadas, a atenção deverá ser redobrada, pois as condições ambientais são extremamente favoráveis à evolução dos estádios de vida livre dos parasitos (LIMA, 2008). 
SILVA, S.C. et al. Verminose em rebanhos ovinos. PUBVET, Londrina, V. 5, N. 1, Ed. 148, Art. 996, 2011.

\subsubsection{Nível nutricional dos ovinos}

A nutrição é um dos fatores que mais influenciam o desempenho dos animais, desde o estabelecimento da puberdade até o número de cordeiros produzidos durante a vida útil do animal Animais sujeitos a uma criação mais intensiva são forçados a se alimentar sem muita seletividade e próximos aos bolos fecais. Isto faz com que adquiram cargas maiores de vermes (VILLA, 2008).

Visto que animais submetidos a baixo nível nutricional tornam-se mais susceptíveis ao parasitismo, por não terem condições de desenvolver uma resposta imunitária efetiva. Dessa forma, ao se preconizar práticas de controle parasitário, o manejo nutricional do rebanho deve ser considerado. Entretanto, tem sido observado que este fator isolado não impede que nos períodos com grande quantidade de larvas nas pastagens, mesmo animais mantidos em boas condições nutricionais, adquiram altos níveis de infecção, com altas taxas de morbidade e mortalidade (VIEIRA, 2003).

O número de animais por unidade de área é outro fator que tem influência significativa no nível de contaminação das pastagens. Uma lotação animal elevada predispõe ao aparecimento de surtos de verminose; nesta situação, a vigilância deve ser redobrada. Pastagens com melhor qualidade e elevado valor nutritivo, representam a melhor alternativa para a obtenção de animais bem nutridos e para a diminuição de gastos com suplementação e medicamentos, e são uma alternativa estratégica na alimentação de animais adultos ou que saíram das fases de crescimento mais acentuado (VERISSIMO, 2008).

O consumo de dietas ricas em proteína pode incrementar a produção de células de defesa (anticorpos) evitando o aparecimento da verminose (HASSUM, 2009), teoria esta confirmada por Veloso et al. (2006) que constataram que a partir do terceiro mês, os ovinos que receberam alto nível de proteína apresentaram valores de OPG inferiores ao do grupo de baixa proteína $(P<0,05)$, mantendo esse comportamento até o final do experimento (Figura 4), indicando que a alta concentração de proteína alimentar influenciou 
SILVA, S.C. et al. Verminose em rebanhos ovinos. PUBVET, Londrina, V. 5, N. 1, Ed. 148, Art. 996, 2011.

na redução do número de vermes presentes no trato gastrintestinal desses animais.

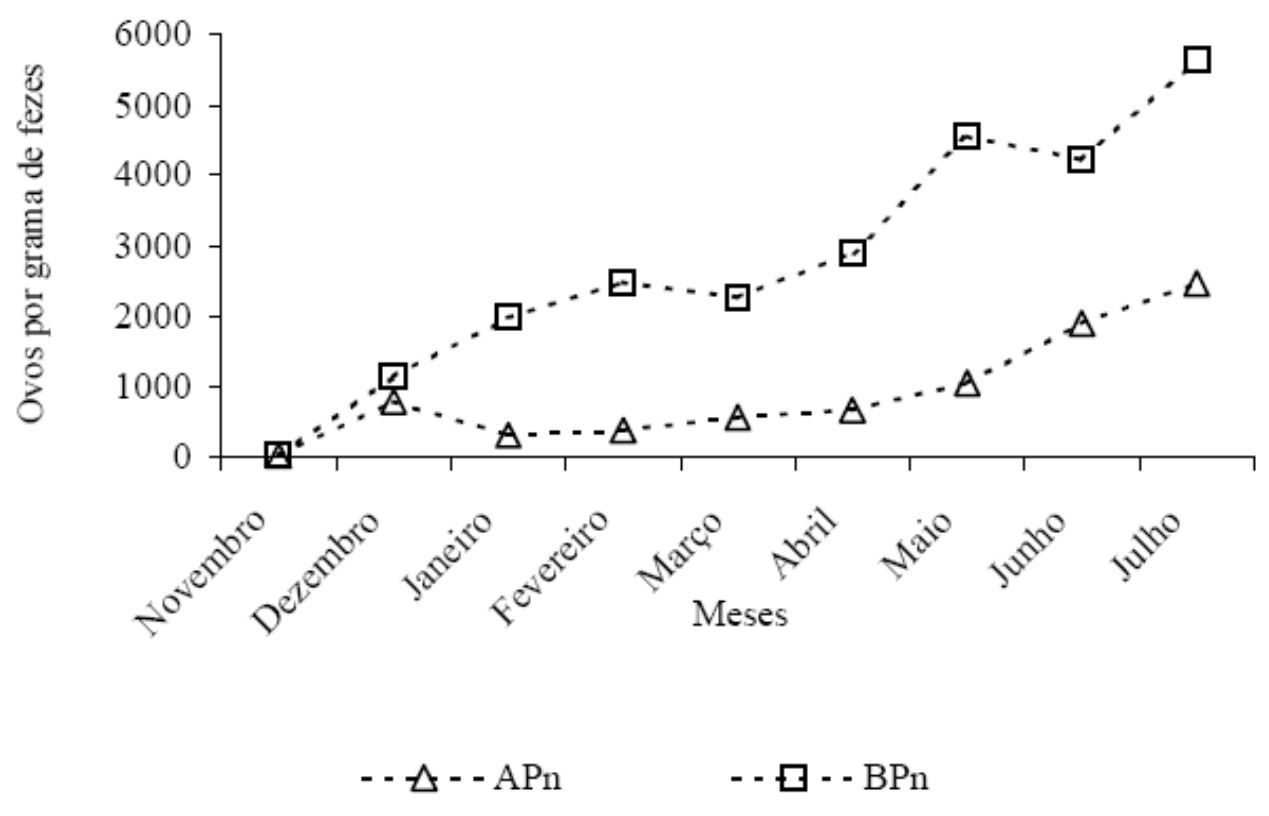

Figura 4. OPG médio em ovinos Santa Inês, suplementados com APn (animais não vermifugados + concentrado com alta proteína) e BPn (animais não vermifugados + concentrado com baixa proteína)., durante o período de novembro de 2000 a julho de 2001, Brasília, DF. (Fonte: Veloso et al., 2006).

\subsection{CONDIÇÕES CLIMÁTICAS}

O estabelecimento de um sistema de criação economicamente viável em determinada região requer a escolha de raças ou variedades que sejam adequadas às condições ambientais locais (BARBOSA et al., 2001).

As condições mais favoráveis para o desenvolvimento do $H$. contortus ocorrem durante o outono, quando as temperaturas mínimas estão acima de $10^{\circ} \mathrm{C}$ e há um bom equilíbrio entre precipitação e evaporação (VIEIRA, 2005). 
SILVA, S.C. et al. Verminose em rebanhos ovinos. PUBVET, Londrina, V. 5, N. 1, Ed. 148, Art. 996, 2011.

Amarante (2001) observou que em temperaturas elevadas, ao mesmo tempo em que aceleram o desenvolvimento larval (ovo até larva infectante), podem reduzir o tempo de sobrevivência das larvas no ambiente.

Os parasitas são eliminados nas fezes dos animais na forma de ovo e necessitam de condições ambientais com temperatura ótima em torno de 22$28^{\circ} \mathrm{C}$ e umidade relativa superior a $80 \%$, ou seja, um ambiente quente e úmido, que pode ser encontrado na maior parte do país, particularmente na época chuvosa. A textura do solo e o hábito de crescimento da planta forrageira influenciam o microclima criado no ecossistema da pastagem, determinando o grau de umidade do solo e, o nível de incidência solar e ventilação na base do dossel (JOHNSTONE, 2008).

As L3 migram do bolo fecal para as pastagens, principalmente na parte da manhã e no final da tarde, quando a intensidade de luz é menor. As L3 não migram todas ao mesmo tempo e sim em forma de onda e esta migração está diretamente relacionada à umidade (chuvas, orvalho). No período da seca, a maioria das L3 fica no bolo fecal ou próximo a ele, na base das plantas. No período das chuvas as $\mathrm{L} 3$ podem migrar em torno de $90 \mathrm{~cm}$ do bolo fecal. A maioria das L3 de Cooperia, Haemonchus, Oesophagostomum, Trichostrongylus e Bunostomum são recuperadas do bolo fecal até 4 meses após a contaminação das pastagens, entretanto, algumas L3 podem permanecer viáveis por vários meses (LIMA, 2008)

Outro fator a ser levado em consideração é o índice pluviométrico; verões com altas precipitações favorecem o aparecimento de surtos de verminose, requerendo, portanto, um maior número de dosificações anti-helmínticas. Por outro lado, nos períodos secos ocorre uma maior mortalidade dos estádios de vida livre, sendo recomendável à aplicação tática de anti-helmínticos para a redução da contaminação das pastagens (ECHEVARRIA et al., 2008).

Amarante et al. (1996) realizaram experimento no qual ocorreu seca severa em junho, julho e agosto (precipitações inferiores a $23 \mathrm{~mm}$ ), sendo que em junho foi registrado apenas 2,5 mm. Nesse período, registraram-se números excessivos de larvas infectantes de nematódeos gastrintestinais na 
SILVA, S.C. et al. Verminose em rebanhos ovinos. PUBVET, Londrina, V. 5, N. 1, Ed. 148, Art. 996, 2011.

pastagem, indicando que provavelmente a estiagem não influenciou desfavoravelmente o desenvolvimento, a sobrevivência e a dinâmica da dispersão larval.

Este fenômeno pode ser explicado por Almeida et al. (2005) no qual relatam que períodos secos com temperaturas amenas podem ser particularmente de risco, visto que as massas fecais podem permanecer íntegras devido à baixa precipitação pluvial, possibilitando a sobrevivência prolongada das larvas no bolo fecal e, posteriormente, em condições favoráveis, uma considerável quantidade de larvas pode alcançar a vegetação.

Ramos et al. (2004) observaram a predominância do $H$. contortus no final da primavera até o inicio do inverno (Figura 5), com maiores intensidades no verão, esta ocorrência é influenciada pelas temperaturas médias acima de $15^{\circ} \mathrm{C}$ e da precipitação pluviométrica com mais de $50 \mathrm{~mm}$. Já o Trichostrongylus axei e Trichostrongylus colubriformis se encontraram em maior frequência do outono ao final do inverno devido à maior adaptação às baixas temperaturas.

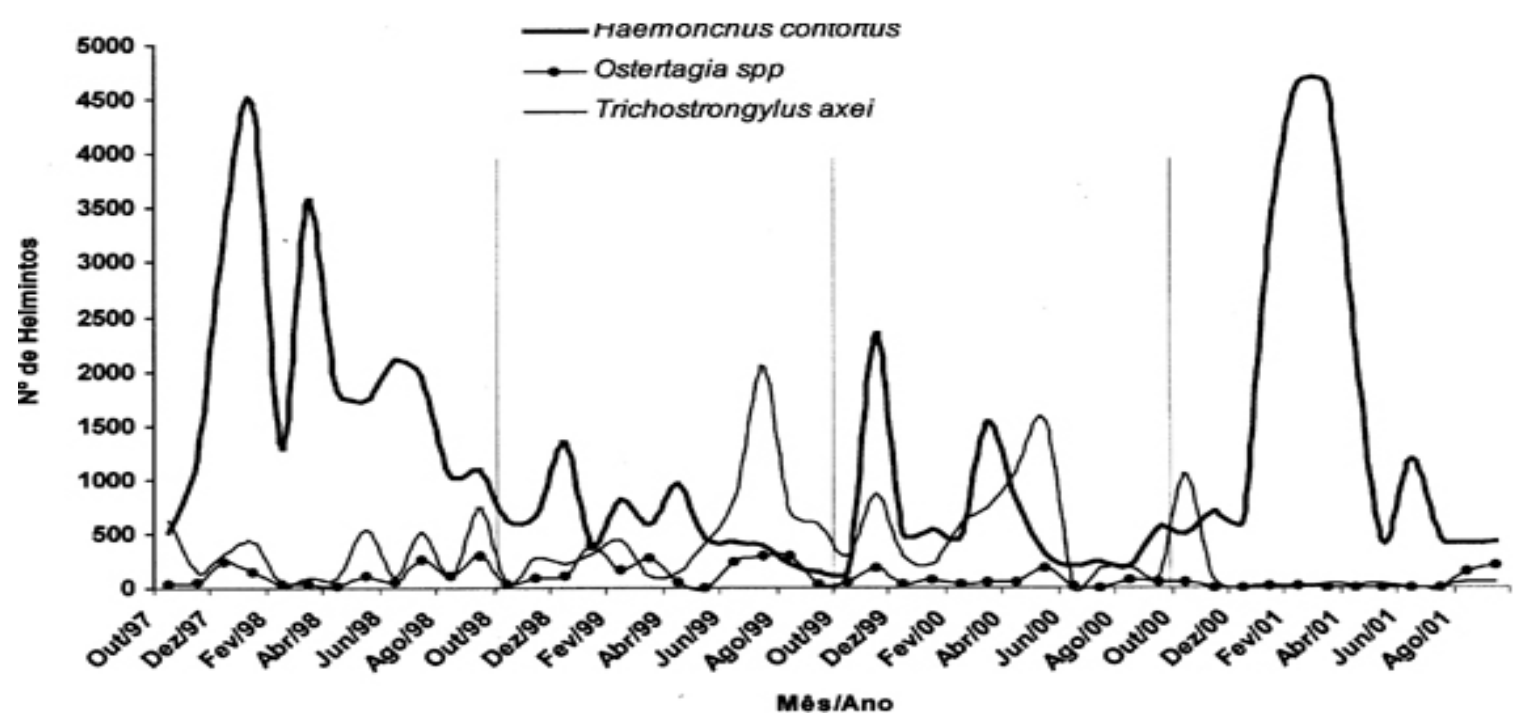

Figura 5: Flutuação estacional de helmintos do abomaso de ovinos, no Planlto Catarinense, no período de outubro de 1997 a setembro de 2001. (Fonte: Ramos et al., 2004). 
SILVA, S.C. et al. Verminose em rebanhos ovinos. PUBVET, Londrina, V. 5, N. 1, Ed. 148, Art. 996, 2011.

\subsection{RESISTÊNCIA ANTI-HELMINTICOS}

A resistência anti-helmíntica é definida como o aumento da habilidade de uma estirpe de parasitos tolerar doses de uma droga, as quais são letais para a maioria dos indivíduos de uma população normal da mesma espécie. Quando um grupo de anti-helmínticos é usado pela primeira vez, o gene ou os genes responsáveis pelo desenvolvimento de estirpes resistentes estão presentes em baixa freqüência numa população normal suscetível. Consequentemente, a eficácia da droga é alta, porém o uso contínuo do mesmo princípio ativo aumenta a freqüência de indivíduos resistentes, baixando a eficácia do produto (FONSECA, 2006).

No passado, a seleção genética de animais com resistência aos nematódeos gastrintestinais ocorreu de forma natural, como resultado da exposição aos parasitas. Posteriormente, os "sobreviventes" foram selecionados para características de importância econômica. Nos últimos 40 anos, houve limitada seleção natural para resistência aos parasitas devido ao surgimento e emprego em larga escala de anti-helmínticos eficientes e de baixo custo (AMARANTE, 2004).

Os medicamentos são usados tanto na prevenção, como no tratamento curativo da enfermidade. Isto quando realizado por meio de tratamentos múltiplos, muitas vezes a intervalos mensais ou quinzenais, ao longo dos anos, aliado a sub-dosagem e rotação rápida dos vermífugos, resultará no surgimento de cepas resistentes aos vários princípios ativos das drogas existentes no mercado de produtos veterinários (SILVA NETTO, 2008).

O controle da verminose gastrintestinal tem sido baseado, quase que exclusivamente, no emprego de três grupos de anti-helmínticos de amplo espectro: benzimidazóis (albendazol, oxfendazol e fenbendazol), imidazotiazóis (levamisol) e lactonas macrocíclicas (ivermectina, abamectina, doramectina e moxidectina) (AMARANTE, 2004), cada um possuindo mecanismo de ação diferenciada, o que deve ser levado em consideração quando de sua substituição de uso (cada ano), para evitar a troca de produtos com a mesma 
SILVA, S.C. et al. Verminose em rebanhos ovinos. PUBVET, Londrina, V. 5, N. 1, Ed. 148, Art. 996, 2011.

base química e conseqüente risco de seleção de parasitos resistentes (MACIEL, 2006).

É importante considerar que em rebanhos onde há problemas de resistência anti-helmíntica, o prejuízo econômico ocasionado pela verminose é mais acentuado, uma vez que além da queda na produtividade do rebanho, os produtores ainda desembolsam recursos financeiros para a aquisição de antihelmínticos, cuja eficácia é altamente comprometida, em função da resistência dos vermes (VIEIRA, 2005).

Por outro lado, uma falta na resposta ao vermífugo não significa, necessariamente, um caso de resistência, pois alguns sintomas clínicos, normalmente associados com o parasitismo gastrintestinal como diarréia, anemia e perda de condição corporal, não são específicos e podem ser devido a outros fatores, tais como: presença de agentes infecciosos, nutrição deficiente, deficiência de elementos minerais e intoxicações por plantas. Outros fatores podem também contribuir para uma aparente falha, tais como, rápida reinfecção devido a alta contaminação da pastagem, a presença de larvas inibidas (hipobióticas) ou em pleno desenvolvimento que não são atingidas pelo anti-helmíntico, defeitos na pistola dosificadora, administração de subdose e escolha errada do vermífugo para o parasita que se deseja controlar. Todos estes problemas por sua vez aceleram o estabelecimento da resistência parasitária (VIEIRA, 2008).

Quando são envolvidas duas drogas de grupos distintos este fenômeno é chamado de resistência cruzada. A resistência múltipla ou resistência antihelmíntica múltipla (RAM) ocorre quando um organismo é resistente a mais de duas bases farmacológicas. Hoje se sabe também que, para muitas drogas, o mecanismo de resistência está ligado ao mecanismo de ação das drogas e conseqüentemente ao processo de seleção (MOLENTO, 2004). 
SILVA, S.C. et al. Verminose em rebanhos ovinos. PUBVET, Londrina, V. 5, N. 1, Ed. 148, Art. 996, 2011.

\subsection{CONTAGEM DE OVOS POR GRAMA (OPG)}

O diagnóstico clínico das infecções por helmintos nos animais domésticos nem sempre é possível, embora muitos sinais clínicos de parasitismo, tais como palidez das mucosas, pêlos sem brilho e diarréia, sejam considerados indicativos de uma pesada carga parasitária. A infecção de animais pelos helmintos que vivem no trato gastrintestinal é usualmente diagnosticada in vivo, através de técnicas laboratoriais com o uso da microscopia óptica. A técnica McMaster, desenvolvida por GORDON \& WHITLOCK (1939), foi originalmente testada e descrita para contagem de ovos de helmintos gastrintestinais de ovinos, sendo mais utilizada para avaliações quantitativas do número de ovos por grama de fezes (FERNANDES et al., 2005).

O exame normalmente é baseado na técnica de contagem de ovos de nematódeos (vermes) por grama de fezes - OPG, que requer dois gramas de fezes ovinas. Apesar da contagem de OPG não representar o número exato de nematódeos (vermes) que parasitam o trato digestório do animal, este exame pode ser utilizado como forma de monitoramento do rebanho, em que uma média de contagem limite é utilizada para se recomendar o tratamento antihelmíntico para ovinos, qual seja: OPG maior ou igual a 500 (HASSUM, 2008).

A amostra de fezes deve ser coletada de preferência pela manhã, diretamente da ampola retal e não do solo, colocadas em um frasco de boca larga (50 $\mathrm{ml}$ de capacidade), com tampa bem vedada ou em sacos plásticos que servirão como luvas no momento em que se fizer a massagem das paredes do reto, amarrando-o após a inversão do mesmo, já com a amostra coletada. Na identificação da amostra pode ser utilizado o nome ou o número do animal. Todas as amostras devem ser colocadas em um único saco plástico. Em seguida amarrar a boca do saco e colocá-lo em isopor com gelo para conservação até chegar ao laboratório para análise (SILVA NETTO, 2007).

A contagem de ovos por grama é uma prática laboratorial largamente empregada não apenas para verificar a sanidade do rebanho, relacionando o 
SILVA, S.C. et al. Verminose em rebanhos ovinos. PUBVET, Londrina, V. 5, N. 1, Ed. 148, Art. 996, 2011.

OPG com a carga parasitária, mas também é muito utilizada na verificação da eficácia de produtos químicos com atividade anti-helmíntica, mediante a redução do número de OPG. Uma boa técnica para ser empregada, deve ser de baixo custo operacional, fácil execução, rapidez, e principalmente de alta sensibilidade na recuperação de ovos (ABIDU et al., 1999).

\section{CONSIDERAÇÕES FINAIS}

O controle da verminose gastrintestinal ovina deve ser centrado em práticas de manejo que minimizem a exposição dos animais às larvas infectantes dos parasitas presentes no ambiente. Neste contexto, destaca-se a possibilidade de integrar a ovinocultura com a criação de outras espécies de herbívoros ou com atividades agrícolas

As medidas de ordem profiláticas devem prevalecer sobre as curativas, pois, estas últimas, representam redução nos lucros. Para que as medidas de controle sanitário e prevenção possam obter resultados concretos e eficazes, faz-se necessário o planejamento e a organização eficiente de toda a estrutura do sistema de produção a nível de rebanho. 
SILVA, S.C. et al. Verminose em rebanhos ovinos. PUBVET, Londrina, V. 5, N. 1, Ed. 148, Art. 996, 2011.

\section{REFERÊNCIAS}

ABIDU, M. et al. Comparação entre a técnica de Mc. Máster e do filtro de Visser para a contagem de ovos de hlemintos gastrintestinais de eqüinos. 1999. Disponível em: <http://www.scielo.cl/scielo.php?pid=S0716-07201999000300009\&script=sci_arttext $>$. Acesso em 20/06/2010.

AGROPOINT. Principais causas de morte em ovinos. 2007. Disponivel em:http://www.agripoint.com.br/default.asp?actA=2\&noticiaID=3397. Acesso em: 25/05/2010.

ALMEIDA, R. L., Desenvolvimento, sobrevivência e distribuição de larvas infectantes de nematóides gastrintestinais de ruminantes, na estação seca da baixada fluminense. Revista. Brasileira. Parasitologia. Rio de Janeiro, v.14, n. 3, p.89-94, 2005.

AMARANTE, A. F. T. Fatores que afetam a resistência dos ovinos à verminose. Instituto de Zootecnia-Nova Odessa, 129p. 2008a.

AMARANTE, A. F. T. Resistência genética a helmintos gastrintestinais. In: V SIMPOSIO BRASLEIRO DE MELHORAMENTO ANIMAL, 5, 2004, Pirassununga. Anais... Pirassununga: Sociedade brasileira de Melhoramento, p.1-10, 2004.

AMARANTE, A. F.T. Controle de Verminoses. In: SEMINÁRIO NORDESTINO DE PECUÁRIA PECNORDESTE 2008, 7, 2008, Fortaleza. Anais... Fortaleza: Universidade Estadual de São Paulo, 2008b.

AMARANTE, A.F.T.; PADOVANI, C.R.; BARBOSA, M.A. Contaminação da pastagem por larvas infectantes de nematódeos gastrintestinais parasitas de bovinos e ovinos em Botucatu-SP. Revista Brasileira de Parasitologia Veterinária, v.5, n.2, p.65-73, 1996.

AMARANTE,A.F.T. Controle de endoparasitoses dos ovinos. In: A PRODUÇÃO ANIMAL NA VISÃO DOS BRASILEIROS, 2001, Piracicaba. Anais... Piracicaba: FEALQ, p.461-473, 2001.

AMARANTE,A.F.T.; BARBOSA,M.A.; OLIVEIRA,M.; SIQUEIRA,E.R. Eliminação de ovos de nematódeos gastrintestinais por ovelhas de quatro raças durante diferentes fases reprodutivas. Pesquisa Agropecuária Brasileira, v.27, n.1, p.47-51, 1992.

BARBOSA, O. R.; et al. Zoneamento bioclimático da ovinocultura no estado do Paraná. Revista Brasileira de Zootecnia, v. 30, n. 2, p. 454-460, 2001.

BELLUZO, C. E. C.; KANETO C. N.; FERREIRA, G. M. Curso de atualização em ovinocultura. UNESP, 110p, 2001.

BERNARDI, J. R. A. et al. Desempenho de cordeiros sob quatro sistemas de produção. Revista. Brasileira de Zootecnia. Viçosa, v.34, n.4, p.1248-1255, jul./ago. 2005.

BUENO, M. S. et al. Fatores que afetam a resistência dos ovinos à verminose. Instituto de Zootecnia-Nova Odessa, 129p, 2008

CARVAlho, U. A; GeSteirA, S; SERRANO, L. A. Alterações Metabólicas no Periparto. 2006. Disponível em <http://www.rehagro.com.br/sitereha. do? cdnoticia =1359>. Acesso em: 30/05/2010.

CHAGAS, A. C. S. et al. Ovinocultura: controle da verminose, mineralização, reprodução e cruzamentos na Embrapa Pecuária Sudeste. Documento 65. São Carlos: Embrapa Pecuária Sudoeste, 43p, 2008.

eChevarria, M. A. F; Pinheiro, C. A; Ribeiro, A. L; Sistema de Criação de Ovinos nos Ambientes Ecológicos do Sul do Rio Grande Do Sul. Embrapa 2008. disponível em: 
SILVA, S.C. et al. Verminose em rebanhos ovinos. PUBVET, Londrina, V. 5, N. 1, Ed. 148, Art. 996, 2011.

<http://sistemasdeproducao.cnptia.embrapa.br/FontesHTML/Ovinos/Criacao OvinosAmbientesEcologicosSulRioGrandeSul/saude.htm\#topo>. Acesso em: 24/04/2010.

FACÓ, O. et al. Raça Morada Nova: Origem, características e perspectivas. Documentos 75. Sobral. Embrapa Caprinos, 41p, 2008.

FERNANDES, M. R. et al., Comparação entre as técnicas mcmaster e centrífugoflutuação para contagem de ovos de nematóides gastrintestinais de ovinos.2005. Disponível em: <http://www.revistas.ufg.br/index.php/vet/article/viewFile/354/329>. Acesso em: $23 / 03 / 2010$

FONSECA, A. D. Helmintoses gastrintestinais dos ruminantes. Universidade Federal do Rio de Janeiro: UFRRP, 12p, 2006.

GATTO, L. Sanidade do rebanho. Lajes, 10 Jun. 2007. Disponível em <http://www.acosc.org.br/acosc/artigos/ac_artigosdetalhes.jsp?codigo=19>. Acesso em: 05 jun. 2010.

GENNARI, M. S.; AMARANTE, A. F. T. Helmintos de ovinos e caprinos. In: II SIMPÓSIO SOBRE INFERMIDADES DE CAPRINOS E OVINOS, 2005, São Paulo. Anais... São Paulo: Instituto Biológico, p. 13-17, 2005.

HASSUM. I. C. Ferramentas complementares para controle da verminose ovina. Rio Grande do Sul. Comunicado técnico, 69. Embrapa Pecuária Sul, 4 p, 2009.

HASSUM. I. C. Instruções para coleta e envio de material para exame parasitológico de fezes OPG e coprocultura para ruminantes. Comunicado técnico, 64. Embrapa Pecuária Sul, 2 p, 2008.

HASTENPFLUG, M.; WOMMER, T. P. Ovinocultura de corte. Campo Grande, 2009. Disponível em <http://w3.ufsm.br/ovinos/index2.php?option=com_docman\&task=doc_ view\&gid=5\&Itemid=29>. Acesso em: 20/05/2010.

IBGE - Instituto Brasileiro de Geografia e Estatística. 2008. Disponível em: http://www.sidra.ibge.gov.br/bda/pecua/default.asp?t $=2 \& z=t \& o=22 \& u 1=1 \& u 3=1 \& u 4=1 \& u 5=$ $1 \& u 6=1 \& u 7=1 \& u 2=3$. Acesso em: 23/05/2010

JOHNSTONE, C. Integrando manejo da pastagem e controle da verminose. 2008. Disponível em: < http://www.portalovinos.com.br/materias_ler.php?id=38>. Acesso em: 25/05/2010.

KATIKI, L. M. et al. Controle parasitológico através da nutrição de ovelhas Santa Inês, Morada Nova e Texel em lactação. Artigo Técnico: Instituto de Zootecnia. Nova Odessa, 2007.

LIMA, S. W., Fatores que interferem no Controle das Helmintoses de Bovinos. 2008. Disponível em: <http://cnia.inta.gov.ar/helminto/Congreso\%20Brasil\%202008/Fatores\%20 que $\% 20$ interferem $\% 20$ no $\% 20$ Controle $\% 20$ das $\% 20$ Helmintoses $\% 20$ de $\% 20$ Bovinos.pdf $>$.

Acesso em: 25/03/2010.

LOURENÇO, F. J.;SANTELLO, G. A. Controle de helmintoses em ovinos. Maringá, 30 de mar. 2007.

MACIEL, F. C. Manejo sanitário de caprinos e ovinos: III Série circuito de tecnologias adaptadas para a agricultura familiar. Editora: EMPARN, 34p, 2006.

MACIEL, F. C.; AHID, S. M. M.; MOREIRA, F. R. C. Manejo sanitário de caprinos e ovinos. In: CRIAÇÃO FAMILIAR DE CAPRINOS E OVINOS NO RIO GRANDE DO NORTE: ORIENTAÇÕES PARA VIABILIZAÇÃO DO NEGÓCIO RURAL. Natal, Anais... Natal:, p. 391-426, 2006.

MACIEL, T. Verminoses em ovinos - um fator limitante em sistemas de produção. Artigo Técnico. Rehagro, 2008. 
SILVA, S.C. et al. Verminose em rebanhos ovinos. PUBVET, Londrina, V. 5, N. 1, Ed. 148, Art. 996, 2011.

MEXIA, A. A; Desempenho Reprodutivo e Produtivo, e Infecção por Helmintos em Ovelhas. Maringá: UEM, 2002. 48p. Dissertação (Mestrado em Produção Animal) Universidade Estadual de Maringá, UEM, 2002.

MOLENTO, M. B. Resistência de Helmintos em Ovinos e Caprinos. XIII Congresso Brasileiro de Parasitologia Veterinária e I Simpósio Latino-Americano de Ricketisioses, Ouro Preto, MG. Revista Brasileira Parasitologia Veterinária, v.13, suplemento 1, 2004.

MORAES, F. R. Uso de marcadores imunológicos na avaliação da resposta imune dos ovinos à infecção natural por nematódeos e na seleção de animais resistentes às parasitoses. Curitiba, 2002. 194f. Universidade Federal do Paraná. Dissertação (Mestrado em Produção Animial)- Setor de Ciências Agrárias, Universidade Federal do Paraná.

NUNES, A. P. et al. Estudo da Variabilidade Genética de Resistência a Nematódeos Gastrintestinais em Ovinos da Raça Corriedale com Marcadores RAPD. Revista Brasileira de Agrociência, Pelotas, v. 13, n. 1, p. 25-33, jan./mar. 2007.

OliveIRA, E. L.; F. H. M. A. R. DE ALBUQUERQUE. Manejo Sanitário de pequenos ruminantes. Documentos 77. Sobral: Embrapa Caprinos, 26p, 2008.

OTTO, C. et al., Eliminação de ovos de nematódeos por ovelhas naturalmente infectadas durante diferentes fases reprodutivas. Curitiba, 1994. Disponível em <http://www.crisa.vet.br/publi_2001/nota2.htm> Acesso em: 10 mai. 2010.

OTTO, C.; BONA, F.A.; SÁ, J.L.; et al. Eliminação de ovos de nematódeos por ovelhas naturalmente infectadas durante diferentes fases reprodutivas. Revista do Setor de Ciências Agrárias. n.13, p.161-166, 1994.

PEREIRA, A. B. L; LEITE, R, C.; BIANCHIN, I. Verminose dos Bovinos. In: SIMPOSIO PFIZER SOBRE VERMINOSE BOVINA, 2, 2005. Anais... São Paulo: Pfizer, p. 1-14, 2005.

QUADROS, D. G.; VIELMO, A. C. Pesquisa realizada pela uneb pode auxiliar no controle da verminose em caprinos e ovinos. Barreiras- BA, 6p. Pesquisa. 2004.

QUANDROS, D.G. Nematodioses de ovinos e caprinos mantidos em pastagens no oeste da Bahia. 2004. 120p. Tese (Doutorado em Zootecnia), Faculdade de Ciências Agrárias, Universidade Estadual Paulista "Julio de Mesquita Filho", Jaboticabal, 2004.

RAMOS, C. T. et al. Epidemiologia das helmintoses gastrintestinais de ovinos no Planalto Catarinense. Ciência Rural. Santa Maria, v. 34, n. 6, 6p, nov./dec. 2004.

RODRIGUES, A. B. et al. Sensibilidade dos nematóides gastrintestinais de caprinos a antihelmínticos na mesorregião do Sertão Paraibano. Pesquisa Veterinária Brasileira. Rio de Janeiro, v. 27, n.4, abr. 2007.

RUFINO, L. R. L. Contagem de nematódeos gastrintestinais em ovelhas santa inês no período periparto, no Distrito Federal. 2007. 50p. Dissertação (Mestrado em Ciências Agrárias), Faculdade de Agronomia e Medicina Veterinária, Universidade de Brasília, 2007.

SÁ, J. L.; SÁ, C, O. Controle de parasitas interno em ovinos. Ciências Agrárias. Curitiba, v.13, p.161-166. 1994

SÁ, C. O.; SÁ, J. L.; História dos Ovinos, 2005. Disponível em <http://www.crisa.vet.br/ovino.htm. Acesso em 10/04/2010.

SÁ,J.L.; SÁ,C. O. Recria e terminação de cordeiros em confinamento: Revisão, 2001. Disponível em <http://www.uov.com.br/biblioteca/543/recria_e_terminacao_ de_cordeiros_em_confinamento_revisao.html> Acesso em : 29 mai. 2010.

SASA, A. et al. Infecção helmíntica em ovelhas Santa Inês no periparto criadas na região do Pantanal brasileiro. Revista Brasileira Saúde Prodrução Aninaml., v.9, n.2, p. 321-326, abr/jun, 2008. 
SILVA, S.C. et al. Verminose em rebanhos ovinos. PUBVET, Londrina, V. 5, N. 1, Ed. 148, Art. 996, 2011.

SIDER, L. S. Biologia molecular para o melhoramento de caprinos e ovinos. 2008. Disponível em <http://people.ufpr.br/ freitasjaf/artigoscaprinos/biologiamolecovcap.pdf> Acesso em 15/06/2010.

SILVA NETTO, F. G. Coleta e remessa de material para exame de laboratório. Porto Velho-RO. Folder - Embrapa Rondônia. Jul. 2007.

SILVA NETTO, F. G., Resistência da verminose ovina aos antihelminticos. Disponível em: <http://www. portaldoagronegocio.com.br/conteudo.php?id=27318>. 2008. Acesso em: 30/04/2010.

SUCUPIRA, M.C.A. Perfil metabólico no período periparto. In: FEIRA INTERNACIONAL DE CAPRINOS E OVINOS-FEINCO, 7, 2010, São Paulo. Anais... São Paulo, Universidade do Estado de São Paulo, 6p, 2010.

VECHI, J. B. A criação de ovinos em mato grosso. Uma alternativa para o ingresso de pequenos e médios produtores rurais na atividade. 2004. Disponível em: < http://www.seder.mt.gov.br/arquivos/A_c8e35ceb0ca8142aaaff2f55be2c4114CRIACAO_OVIN OS_PROPOSTA_3.doc> Acesso em 03 abr. 2010.

VELOSO, C.F.M. et al. Efeitos da suplementação protéica no controle da verminose e nas características de carcaça de ovinos Santa Inês. Ciência Animal Brasileira, v.5, n.3, p.131139, 2006.

VERÍSSIMO, C.J. Controle da verminose em ovinos. Artigo Técnico: Instituto de Zootecnia. Nova Odessa, 2008.

VIEIRA, L. S. Alternativas de controle da verminose gastrintestinal dos pequenos ruminantes. In: CONGRESSO PERNAMBUCANO DE MEDICINA VETERINÁRIA, 5, 2003, Recife. Anais... Recife: Sociedade Pernambucana de Medicina Veterinária. 2003. p. 236-246.

VIEIRA, L. S. Métodos alternativos de controle de nematóides gastrintestinais em caprinos e ovinos. In: SIMPÓSIO INTERNACIONAL SOBRE CAPRINOS E OVINOS DE CORTE, 3, 2008, João Pessoa, Anais... João Pessoa, 8p. 2008.

VIEIRA, S. L., O Controle de Verminose na Produção Orgânica de Caprinos e Ovinos. 2005. Disponível em: <http://www.fmvz.unesp.br/Informativos/ovinos/utilid22.htm> . Acesso em: $17 / 02 / 2010$.

VILLA, M. R. A escolha da pastagem correta para os ovinos. 2008. Disponível em:<http://www.sementesfiscalizadas.com.br/informacoes/artigos_tecnicos/vis/vis/?v=46>. Acesso em: 18/05/2010. 